\title{
Simulation of a Model for International Traveler's Check-In Process Using Arena Software Tool
}

\author{
J. L. Obetta, O. O. Olusanyan, M. O. Oyediran*, W. B. Wahab, A. T. Olusesi, A. W. Elegbede \\ Department of Electrical/Electronics and Computer Engineering, Bells University of Technology, Ota, Ogun State, Nigeria \\ Email: *mayor_yoppy02@yahoo.com
}

How to cite this paper: Obetta, J.L., Olusanyan, O.O., Oyediran, M.O., Wahab, W.B., Olusesi, A.T. and Elegbede, A.W. (2021) Simulation of a Model for International Traveler's Check-In Process Using Arena Software Tool. Engineering, 13, 125-134. https://doi.org/10.4236/eng.2021.133010

Received: January 28, 2021

Accepted: March 8, 2021

Published: March 11, 2021

Copyright $\odot 2021$ by author(s) and Scientific Research Publishing Inc. This work is licensed under the Creative Commons Attribution International License (CC BY 4.0).

http://creativecommons.org/licenses/by/4.0/

\begin{abstract}
With the current situation of insecurity in Nigeria and the worsening condition of Nigerian roads, there is increasing demand for air travel. This increasing demand for airline services amidst limited resources results in passenger dissatisfaction and reduction of revenue for airports and airlines. The dynamics of service demand and resource supply result in check-in issues for all the stakeholders in the commercial aviation industry. Hence, this research simulated the developed model for travelers' check-in process at the "D Wing" of the Departure Section of Murtala Muhammed International Airport (MMIA), Ikeja, using Arena Software Tool. The simulation of the developed model was carried out by varying five different configurations of the servers with respect to the baggage weighing machines and passenger profiling devices to obtain the minimum average check-in time (ACT) for the process, with each configuration undergoing 133 completions of simulation runs. The result of the experimentation revealed that the $3 \times 3 \times 4$ configuration of servers produced the smallest ACT of 18.25 minutes. This translates to a difference of about 58 minutes from the 76.16 minutes ACT of the real system; representing about $76 \%$ improvement in the check-in time of passengers. This study contributed to knowledge by revealing that the main choke points in the MMIA check-in system occur at the baggage weighing and passenger profiling areas as against the check-in counter sub-section as advanced by previous works. Furthermore, the research added value to knowledge by creating a balance between customer satisfaction and cost of operations thereby accommodating the interests of the passenger and the operator who are the two main stakeholders in the commercial aviation industry.
\end{abstract}

\section{Keywords}

Modelling, Check-In Process, Arrival Rate, Service Rate, Average Check-In 
Time, Server Configuration

\section{Introduction}

Airports are essential part of the air transport system since they provide the entire infrastructure needed to enable passengers, baggage and freight to transfer from surface and maritime modes to air mode of transport and to allow airplanes to take off and land [1]. A typical example of such is MMIA Ikeja. According to the National Bureau of Statistics (NBS), the international terminal of MMIA (it-MMIA) served a total of 3,227,952 passengers in 2010. This figure increased by 358,790 passengers or $11.12 \%$ in 2011 . Furthermore, the number of passengers rose by 854,188 (or 23.82\%) to reach 4,440,930 passengers in 2012 [2]. It is instructive to state that despite these yearly increases in international air passenger traffic through the MMIA, the facilities had remained unchanged since the 2007 improvements on facilities. This situation results in regular queues at the check-in section at the departure hall [1]. Remarkably, queues and the efforts to eliminate them are necessary in order to have an organized system or society [3].

In order to undertake any commercial flight with passengers, airlines critically concentrate their efforts on the verification and confirmation of the identity of outbound passengers. This service, which is referred to as the check-in process, is usually carried out at the departure hall of the airport terminal. The check-in process is an enormous task involving many stakeholders, some of who are not staff of the airlines and are therefore not under their control. The task has become even more challenging following the stringent security measures incorporated in the air transport industry following the tragic event of September 11, 2001 in the United States of America [4], where some travelers who were checked-in as normal passengers later turned out not to be.

Check-in processing is characterized by various activities, major of which is the initial security screening, identification, verification and confirmation of travelers' identities as contained in the travel documents, as well as the identification, weighing and acceptance of travelers' baggage and freight. The process of identifying, verifying, confirming travelers' identities, and their baggage by both of the airport and airline staff, as well as other governmental security agencies is time consuming. However, by design, airlines have an average time estimated to service a particular passenger at the counter and check-in counter staff always attempt to adhere to this timing.

Usually, passengers arrive the departure hall for check-in activities at random, and for most times, the arrival rate is greater than the estimated service rate. At the commencement of the check-in process, passengers' arrival rate is usually lower than the estimated service rate. However, as the scheduled departure time draws nearer, the arrival rate of passengers increases exponentially in a highly-random manner, and becoming much higher than the estimated service rate. 
Since passengers' arrival rate is random and therefore unpredictable, this leads to a build-up of a queue of passengers waiting to be served. When passengers' queue build-up, the problem of prolonged waiting on the line arises. At this point, passengers' start becoming agitated for fear of missing their flights as this has various implications. As the situation continues, it sometimes leads to delayed flights with the associated consequences on airlines, passengers and airport management. Eventually, the series of delays result to problems for both the airlines and their esteemed passengers, leading to loss of revenues, travel time and passenger dissatisfaction.

Recognizing the existence of queues and its impact on organizations, various researchers have sought ways to address the queue problem. A major effort in this regard was proposed by Agner Krarup Erlang, a Danish engineer who worked for the Copenhagen Telephone Exchange [5]. Furthermore, Winston (1991) described queueing theory as a branch of mathematics that studies and models the act of waiting in lines. Similarly, [6], described queueing theory as the theory behind what happens when you have lots of jobs, scarce resources, and subsequently, long queues and delays. The consequences of this include wastage of scarce resources, customer dissatisfaction, and most times, unexecuted businesses.

In an attempt to address the queue problem, [7] were of the opinion that doubling service demand in queue situations does not necessarily require resources increase to achieve better performance. Another group of researchers, [8], investigated the number of critical resources at the first two phases of the airport departure operations and found that most passengers are not satisfied with the services received at the airport check-in process. Similarly, [9], applied the Discrete Event Simulation (DES) model to evaluate how arrival patterns of passengers to the airport departure hall affects international terminal operations such as check-in, security screening and immigration control. The researcher found that arrival pattern is a major factor responsible for overcrowding at the check-in section of airports. [3], investigated traveler's flow process in both the MMIA and Nnamdi Azikiwe International Airport (NAIA), Abuja and recommended multiple server multiple queue structure to address airport check-in problem at the check-in counter sub-section as a way of addressing passenger dissatisfaction. [1] adopted the Spearman Rank correlation method using weighted average and Gap analysis to examine the relationship between passengers' satisfaction and service quality in MMIA. Yet, [4], proposed the integration of a biometric system into the check-in process to enhance the airport operators' performance. The researcher built a model of a medium-sized airport and analyzed the model using the Simio simulation environment and used it to evaluate the expected performance of the Biometric Single Token Identification (BST ID). The result of the simulation models reported more than $90 \%$ decrease in check-in time from 47.98 minutes for manual check-in passengers to $3.6 \mathrm{mi}-$ nutes for BST ID compliant passengers. This research simulated the developed check-in process model at the international terminal of MMIA, Ikeja with a view 
to proposing an improved model that will address the airport check-in process queue problem, as well as effectively handle higher airport passenger traffic using cost effective option.

Although check-in process at the airports is generally regarded as activities that take place at the airline check-in counter, the process actually starts at the airport departure hall entrance and terminates at the airline check-in counter. Thus, this research covers the activities that take place at the four distinct sections of the airport check-in section, which includes departure hall access/security screening gates, baggage weighing sub-section, passenger profiling sub-section, and airline check-in counter sub-section. Also, this study revealed that the main choke points in the MMIA check-in system occur at the baggage weighing and passenger profiling areas as against the check-in counter sub-section as advanced by previous works.

\section{Methodology}

The developed model was subjected to simulation (experimentation) having undergone validation stage and it was confirmed that the developed model represented the real-life system under study.

Due to the complex nature of international air travel, passengers at the international terminal of the MMIA are usually subjected to different processes before getting to the airline check-in counter point. These processes can be generally categorized into four (4) main service activities: initial security screening at the entrance gates, baggage weighing, passenger profiling and check-in counter activities, all leading to the issuance of boarding pass to the passenger. At the MMIA Departure Hall, each of these sub-sections is characterized by a unique process that is serviced by designated servers. It was further observed that Emirates airline uses six check-in counters; one each for first and Business class passengers while four check-in counters are allocated to Economy class passengers. Field work also revealed that both the first and Business class passengers do not witness delays during check-in, while delays are evident with the Economy class group. Thus, the focus of this research is on the Economy class passengers' check-in processing which is usually characterized by delays leading to queues and long waiting times. Generally, and also for the purpose of this study, airport check-in starts at the departure hall entrance and terminates at the airline check-in counter after the boarding pass has been issued to the passenger. Check-in is therefore assumed to be completed immediately after the boarding pass is issued to the passenger.

Following the positive result from the developed model, simulation experiments were carried out by varying the resources at the baggage weighing and passenger profiling sub-sections. This was used to determine the best combination of resources that would give the smallest ACT for passengers. Thus, it was observed that the resource combination of $3 \times 3 \times 4$ servers resulted in the smallest ACT of 18.25 minutes. 
Evaluation is the process of experimenting with the developed model by varying some parameters of the model with a view to testing its performance. It will be recalled that the number of check-in counters allocated to Emirates Economy class is four (4). Thus, the evaluation process maintained the same number of counters. For this study, the 2 sub-sections whose parameters were varied are the baggage weighing and passenger profiling areas. The servers' configuration for the real-life system and also the modelled system is $1 \times 1 \times 4$ servers. Simulation was therefore performed on each addition of a server and corresponding result was obtained. The block diagram of the modified International Traveler's Check-in Process (ITCP) Model is shown in Figure 1. The four coloured boxes represent the resources ( 2 weighing machines and 2 profiling devices, together with the human resource to operate the equipment), that were introduced into the system during experimentation to evaluate the performance of the model. Figure 2 is the modified ITCP Model for the MMIA.

\section{Results and Discussion}

The Developed Model for International Traveler's Check-in Scheme reflects the physical setup of the Emirates check-in process zone at the international terminal of the MMIA. The 3 main sub-sections of the model include the baggage weighing, passenger profiling and check-in counter. Figure 2 is the modified model of the system which was developed using ARENA modelling software tool.

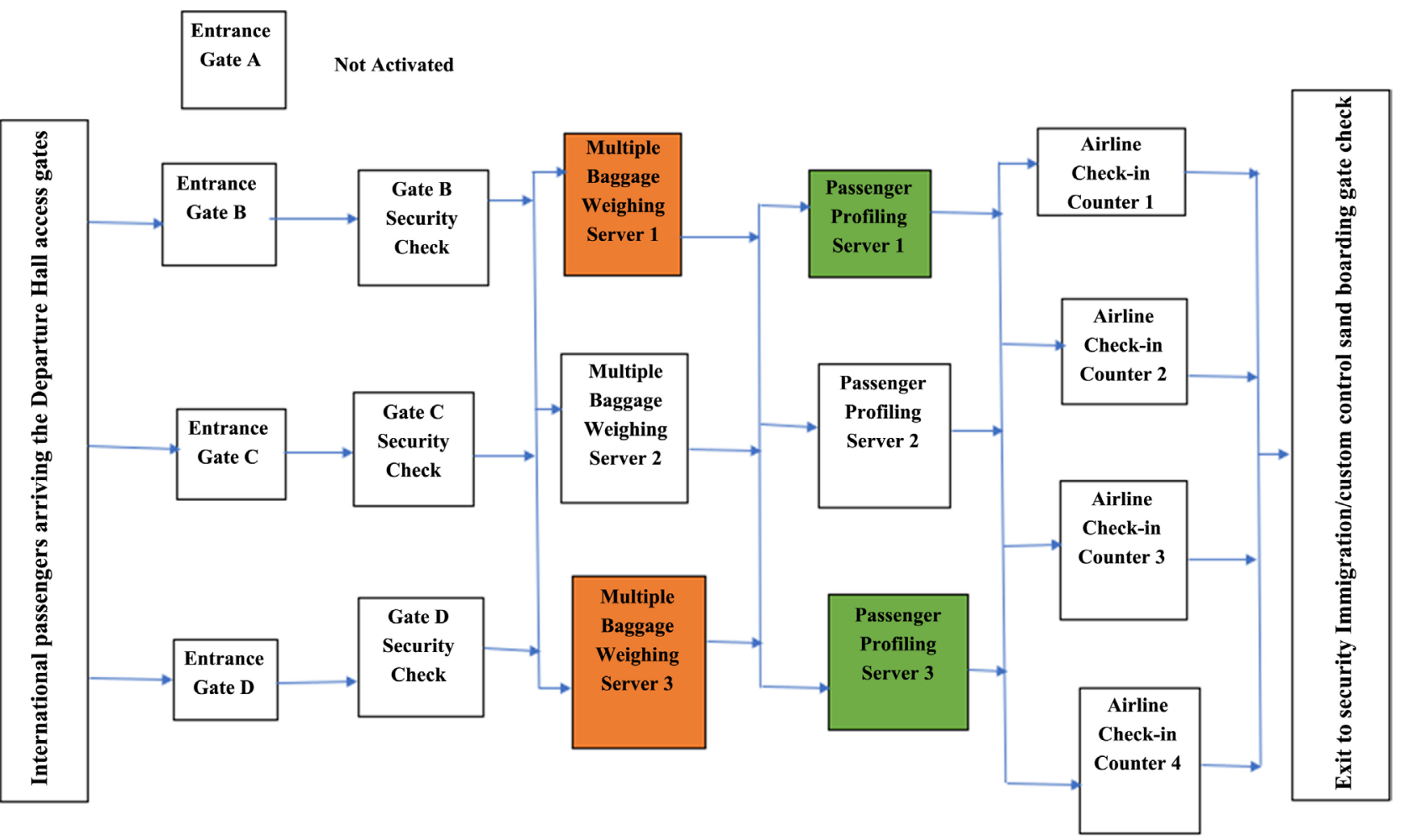

Figure 1. Block diagram of the modified international traveler's check-in process model. 


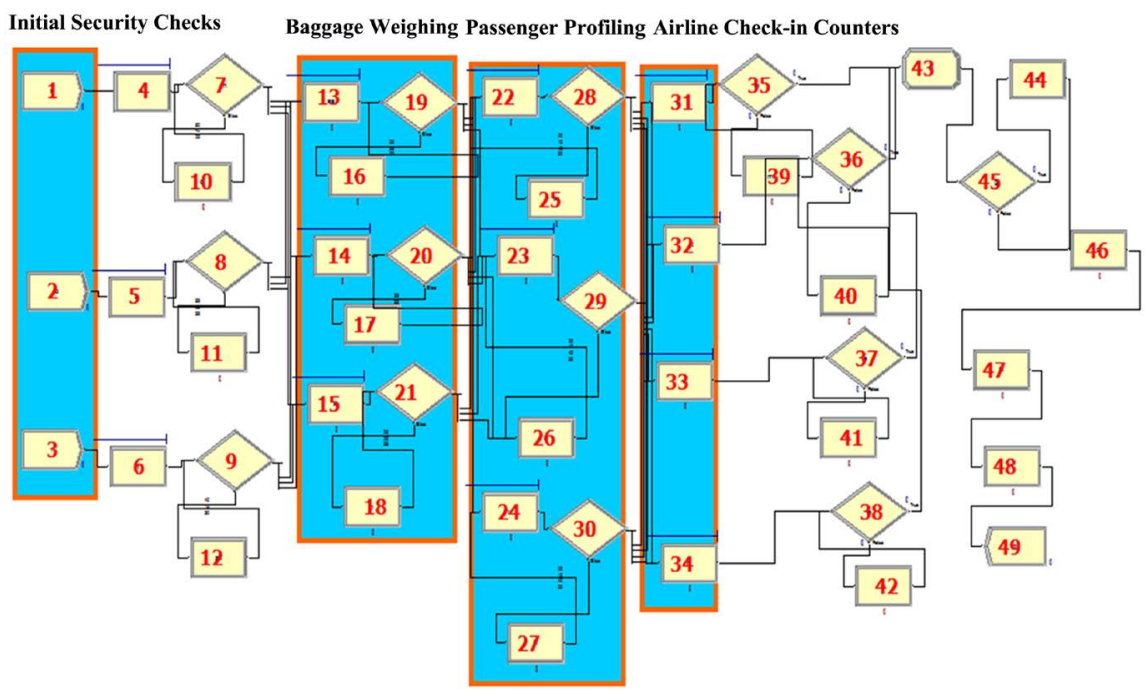

Figure 2. The modified international traveler's check-in process model for MMIA (Table 1).

Table 1. Labelling legend for Figure 2.

\begin{tabular}{|c|c|c|}
\hline Entity Number & Entity Acronym & Meaning \\
\hline 1 & Gate B & Entrance B \\
\hline 2 & Gate C & Entrance C \\
\hline 3 & Gate D & Entrance D \\
\hline 4 & SCQ_1 & Security Check Queue1 \\
\hline 5 & SCQ_2 & Security Check Queue2 \\
\hline 6 & SCQ_3 & Security Check Queue3 \\
\hline 7 & SC_1 & Is Security Check-in_1 successful? \\
\hline 8 & SC_2 & Is Security Check-in_2 successful? \\
\hline 9 & SC_3 & Is Security Check-in_3 successful? \\
\hline 10 & R1_1 & Remediation 1 for Security Check Queue1 \\
\hline 11 & R1_2 & Remediation 1 for Security Check Queue2 \\
\hline 12 & R1_3 & Remediation 1 for Security Check Queue3 \\
\hline 13 & BWQ1 & Baggage Weighing Queue1 \\
\hline 14 & BWQ2 & Baggage Weighing Queue2 \\
\hline 15 & BWQ3 & Baggage Weighing Queue3 \\
\hline 16 & R2_1 & Remediation2 for Baggage Weighing Queue1 \\
\hline 17 & R2_2 & Remediation2 for Baggage Weighing Queue2 \\
\hline 18 & R2_3 & Remediation2 for Baggage Weighing Queue3 \\
\hline 19 & WO1 & Is Weight Ok for Baggage Weighing Queue1? \\
\hline 20 & WO2 & Is Weight Ok for Baggage Weighing Queue2? \\
\hline 21 & WO3 & Is Weight Ok for Baggage Weighing Queue3? \\
\hline 22 & PPQ1 & Passenger Profiling Queue1 \\
\hline
\end{tabular}




\section{Continued}

\begin{tabular}{|c|c|c|}
\hline 23 & PPQ2 & Passenger Profiling Queue2 \\
\hline 24 & PPQ3 & Passenger Profiling Queue3 \\
\hline 25 & R3_1 & Remediation3 for Passenger Profiling Queue1 \\
\hline 26 & R3_2 & Remediation 3 for Passenger Profiling Queue2 \\
\hline 27 & R3_3 & Remediation3 for Passenger Profiling Queue3 \\
\hline 28 & PO1 & Is Profiling Ok for Queue1? \\
\hline 29 & $\mathrm{PO} 2$ & Is Profiling Ok for Queue2? \\
\hline 30 & $\mathrm{PO} 3$ & Is Profiling Ok for Queue3? \\
\hline 31 & CCQ1 & Check-in Counter Queue1 \\
\hline 32 & CCQ2 & Check-in Counter Queue2 \\
\hline 33 & CCQ3 & Check-in Counter Queue3 \\
\hline 34 & CCQ4 & Check-in Counter Queue4 \\
\hline 35 & IVCC1 & Is information Valid for Check-in Counter 1 \\
\hline 36 & IVCC2 & Is information Valid for Check-in Counter 2 \\
\hline 37 & IVCC3 & Is information Valid for Check-in Counter 3 \\
\hline 38 & IVCC4 & Is information Valid for Check-in Counter 4 \\
\hline 39 & R4_1 & Remediation 4 for Check-in Counter 1 \\
\hline 40 & $\mathrm{R} 4 \_2$ & Remediation 4 for Check-in Counter 2 \\
\hline 41 & $\mathrm{R} 4 \_3$ & Remediation 4 for Check-in Counter 3 \\
\hline 42 & R4_4 & Remediation 4 for Check-in Counter 4 \\
\hline 43 & SA & Seat Allotted \\
\hline 44 & АРBP & Agent Processes Boarding Pass \\
\hline 45 & $\mathrm{BC}$ & Is Baggage Check-in? \\
\hline 46 & BPP & Boarding Pass printed \\
\hline 47 & BMHS & Baggage Moves to Handling Section \\
\hline 48 & ТCBP & Traveler Collects Boarding Pass \\
\hline 49 & FT & Flight Takeoff \\
\hline
\end{tabular}

During the simulation experiments, the number of servers in both the baggage weighing and passenger profiling sub-sections were varied between one unit to three units in order to determine the effect of the variations on the average check-in time of passengers. It should be noted that the number of Check-in Counters (CCs) remained constant at 4, being the total number of counters regularly activated for Emirates airline for Economy Class check-in processing. It is also important to note that with respect to time function, passengers are categorized into 2: those with baggage for check-in and those without baggage; designated in the report as "b" and "a" respectively. The following are 6 combinations of the servers used in simulation experiments:

1) $1 \times 1 \times 4$ servers representing $1 \mathrm{WM}, 1 \mathrm{PD}$ and $4 \mathrm{CC}$. 
2) $2 \times 1 \times 4$ servers representing $2 \mathrm{WM}, 1 \mathrm{PD}$ and $4 \mathrm{CC}$.

3) $3 \times 1 \times 4$ servers representing $3 \mathrm{WM}, 1 \mathrm{PD}$ and $4 \mathrm{CC}$.

4) $2 \times 2 \times 4$ servers representing $2 \mathrm{WM}, 2 \mathrm{PD}$ and $4 \mathrm{CC}$.

5) $3 \times 2 \times 4$ servers representing $3 \mathrm{WM}, 2 \mathrm{PD}$ and $4 \mathrm{CC}$.

6) $3 \times 3 \times 4$ servers representing $3 \mathrm{WM}, 3 \mathrm{PD}$ and $4 \mathrm{CC}$.

where:

$\mathrm{WM}=$ Weighing Machine.

$\mathrm{PD}=$ Profiling Device.

$\mathrm{CC}=$ Check-in Counter.

The results were therefore used to determine the average check-in time for a passenger. Mathematically, the average check-in time $\left(T_{A C}\right)$ is modelled as:

$$
T_{A C}=1 / 3\left(T_{Q}+T_{R}+T_{S}\right) \text {. }
$$

where:

$T_{Q}=$ time spent on queue.

$T_{R}=$ time spent on remediation.

$T_{S}=$ time spent being served.

The summary of results of experiments for different configurations of servers is shown in Table 2 and Figure 3. The simulation results showed that the $3 \times 3$

Table 2. Summary result of ACTs for all simulation runs for 6 configurations of servers.

\begin{tabular}{ccc}
\hline Configuration & Resources Combination & ACT (Minutes) \\
\hline 1 & 1 WM, 1 PD, 4 CC $(1 \times 1 \times 4)$ & 79.93 \\
2 & $2 \mathrm{WM}, 1 \mathrm{PD}, 4 \mathrm{CC}(2 \times 1 \times 4)$ & 74.52 \\
3 & $3 \mathrm{WM}, 1 \mathrm{PD}, 4 \mathrm{CC}(3 \times 1 \times 4)$ & 102.35 \\
4 & $2 \mathrm{WM}, 2 \mathrm{PD}, 4 \mathrm{CC}(2 \times 2 \times 4)$ & 30.21 \\
5 & $3 \mathrm{WM}, 2 \mathrm{PD}, 4 \mathrm{CC}(3 \times 2 \times 4)$ & 22.11 \\
6 & $3 \mathrm{WM}, 3 \mathrm{PD}, 4 \mathrm{CC}(3 \times 3 \times 4)$ & 18.25 \\
\hline
\end{tabular}

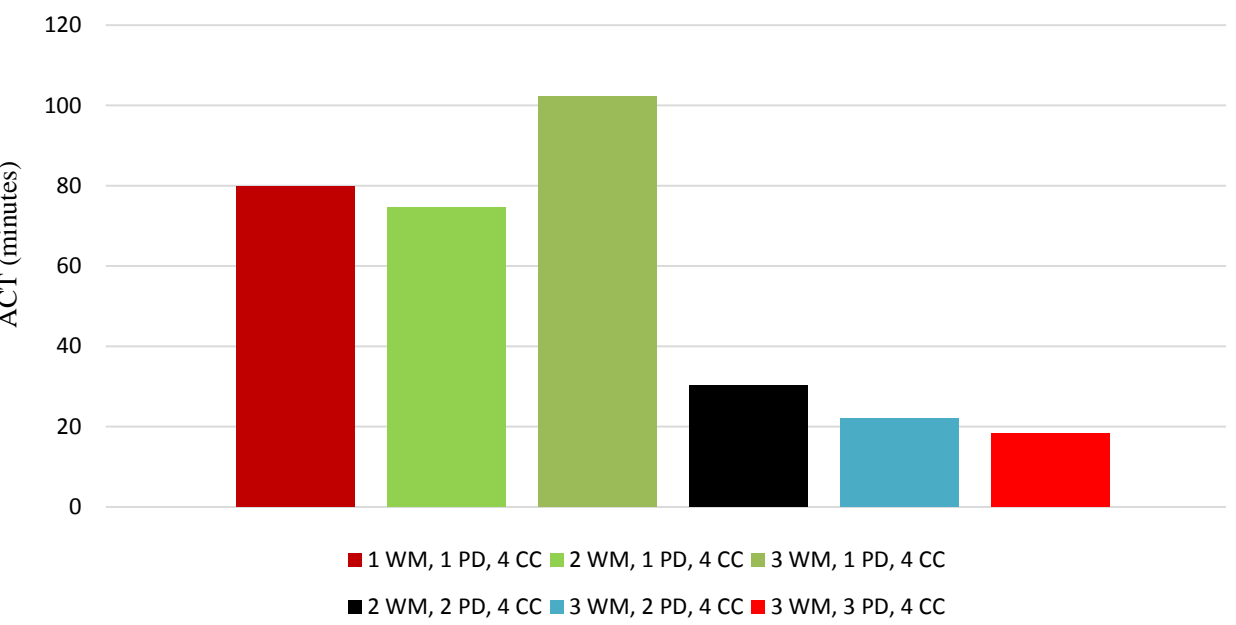

Server Configuration

Figure 3. Result of simulation experiments for 6 configurations of servers. 
$\times 4$ combination of servers decreased the ACT per passenger from 76.16 minutes to 18.25 minutes; which is very significant. Thus, this combination will ensure optimum customer satisfaction as it offers little delay during the check-in process and is therefore proposed as an improvement to the existing model.

\section{Conclusion, Recommendation and Future Work}

In this work, a model for international traveler's check-in process was developed for the international terminal of the MMIA, Ikeja. The developed model yielded an ACT of 18.25 minutes as against ACT of 76.16 minutes for the real system. This represents a difference of 58 minutes from that of the real system; translating to about $76 \%$ improvement on the ACT of the real system. The experimental result showed that the developed model is valid and is therefore useful for airline decision makers to manage passengers' check-in problem as a way of reducing passengers' waiting time, improving the quality of service, enhancing overall customer experience, as well as boosting organizational revenue. Furthermore, the validity of the model indicates that the present facilities of the case study are inadequate to cater for the finite population of passengers. The developed model showed that the main choke points in airport check-in system occur at the baggage weighing and passenger profiling sub-sections. This is contrary to previous research findings that presented the check-in counters as the main choke points. This finding is considered a novel contribution to knowledge. Future work on the airport check-in process problem may look into a system that will ensure that arrival of passengers to the airport is not at random; which ultimately will discourage overcrowding at the check-in section.

\section{Conflicts of Interest}

The authors declare no conflicts of interest regarding the publication of this paper.

\section{References}

[1] Adeniran, A.O. and Fadare, S.O. (2018) Relationship between Passengers' Satisfaction and Service Quality in Murtala Muhammed International Airport, Lagos, Nigeria. International Journal of Research in Industrial Engineering, 7, 349-369.

[2] National Bureau of Statistics (2018) Air Transportation Data, $4^{\text {th }}$ Quarter and Full Year 2017.

[3] Alamutu, S.A. (2018) Application of Queuing Model to Ease Traveler's Flow in Nigerian International Airports. Journal of Business and Management, 20, 17-28.

[4] Patel, V. (2018) Airport Passenger Processing Technology: A Biometric Airport Journey. Master's Degree Thesis, Embry-Riddle Aeronautical University, Prescott, 5-12.

[5] Heyde, C.C., Heyde, C.C., Seneta, E., Crépel, P., Fienberg, S.E., Gani, J. and Erlang, A.K. (2001) Statisticians of the Centuries. Springer, New York, 328-330. https://doi.org/10.1007/978-1-4613-0179-0 70

[6] Harchol-Balter, M. (2013) Performance Modeling and Design of Computer Sys- 
tems: Queueing Theory in Action. Cambridge University Press, Cambridge.

[7] Enciso, J., Vargas, J. and Martinez, P. (2016) Modeling and Simulation of Passenger Traffic in a National Airport. 14th LACCEI International Multi-Conference for Engineering, Education, and Technology, San Jose, 20-22 July 2016, 1-8. https://doi.org/10.18687/LACCEI2016.1.1.217

[8] Adacher, L., Flamini, M., Guaita, M. and Romano, E. (2017) A Model to Optimize the Airport Terminal Departure Operations. Transportation Research Procedia, 27, 53-60. https://doi.org/10.1016/j.trpro.2017.12.151

[9] Alodhaibi, S.S., Burdett, R.L. and Yarlagadda, P.K. (2019) Impact of Passenger-Arrival Patterns in Outbound Processes of Airports. Proceedia Manufacturing, 30, 323-330. https://doi.org/10.1016/j.promfg.2019.02.046 